\title{
EDUCAÇÃO PERMANENTE E CERTIFICAÇÃO DAS APRENDIZAGENS NÃO-FORMAIS E INFORMAIS \\ O CONTEXTO ITALIANO (EUROPA) E BRASILEIRO
}

\author{
LIFELONG LEARNING AND CERTIFICATION OF NON-FORMAL AND INFORMAL \\ LEARNING: THE ITALIAN CONTEXT (EUROPE) AND BRAZILIAN
}

EDUCACIÓN PERMANENTE Y CERTIFICACIÓN DE LOS APRENDIZAJES NO FORMALES E INFORMALES: EL CONTEXTO ITALIANO (EUROPA) Y BRASILEÑO

Jocilene Gadioli de Oliveira

Doutora em Ciências Humanas e Sociais. Departamento de Ciências Humanas - Universidade de Ferrara | Itália E-mail: jo.gadiolideoliveira@student.unife.it

Elena Marescotti

Doutora em Pedagogia Geral e Social. Professor Adjunto de Educação de Adultos. Dep. de C. Humanas - Universidade de Ferrara | Itália E-mail: elena.marescotti@student.unife.it

Maddalena Formicuzzi

Doutora em Ciências da Educação e Formação Continuada, Centro de Docimologia - Universidade de Verona. maddalena.formicuzzi@univr.it

REVISTA PEDAGÓGICA

Revista do Programa de Pós-graduação em Educação da Unochapecó | ISSN 1984-1566 Universidade Comunitária da Região de Chapecó | Chapecó-SC, Brasil Como referenciar este artigo: OLIVEIRA, J. G. MARESCOTTI, E. FORMICUZZI, M. Educação permanente e certificação das aprendizagens não-formais e informais: o contexto italiano (Europa) e brasileiro. Revista Pedagógica, Chapecó, v.16, n.33, p. 23-48, Jul./Dez. 2014.

RESUMO: Este trabalho tem como foco a importância da Educação Permanente através da certificação das aprendizagens nãoformais e informais; é uma pesquisa italiana, sobre as práticas italianas e brasileiras, com base nas diretrizes da União Europeia para a aprendizagem permanente, na descrição de iniciativas ou programas que certificam as aprendizagens que o indivíduo pode adquirir no arco da vida. Da mesma forma foi feita a descrição do contexto brasileiro para enfatizar a implementação de ações para o desenvolvimento do indivíduo e da sociedade através da valorização das aprendizagens. Conclui-se este estudo com algumas questões e alguns desafios identificados, mas também com algumas boas práticas para possíveis avanços.

PALAVRAS-CHAVE: Aprendizagem ao longo da vida. Educação Permanente. Validação das aprendizagens informais e não-formais. Educação de adultos.
ABSTRACT: This work is focused on the importance of Lifelong learning through the certification of non-formal and informal learning; it is about an Italian research on the Italian and Brazilian practices, based on the guidelines European Union for long life learning, in the description of initiatives or programs that certify learning that the individual is able to acquire throughout life. Similarly, a description of the Brazilian context to emphasize the implementation of actions for the development of people and society through the enhancement of learning. This study ends with some identified challenges and unanswered questions but it also provides some good practices for possible advances.

KEYWORDS: Lifelong learning.Continuing education.Validation of informaland nonformallearning. Adult education. 
INTRODUÇÃO: PERMANENTE APRENDIZAGENS INFORMAIS

\author{
APRENDIZAGEM \\ E CERTIFICAÇÃO DAS \\ NÃO-FORMAIS E
}

Este artigo parte das indicações europeias relativas à educação permanente e à certificação das aprendizagens, facilitando a compreensão de termos e conceitos que definem o quadro europeu em matéria. Depois disso, discutem-se as implicações dessas indicações, na Itália, que seguem as orientações europeias, e, no, em reconhecer que a educação, a formação e a aprendizagem ao longo da vida (aprendizagem permanente) são fatores que incentivam o desenvolvimento do indivíduo, o acesso à cultura e a cidadania ativa.

A partir das conclusões do Conselho Europeu de Lisboa (Commissione Europea, 2000a), que afirma que a economia e a sociedade devem orientar-se através do conhecimento, os sistemas europeus de instrução e de formação profissional estão no cerne das transformações e terão de se adaptar, assim, todos os Estados Membros, os Conselhos e a Comissão, cada um em suas respectivas áreas de competência foram convidados a apresentar e a identificar estratégias coerentes e medidas práticas com vista à promoção da aprendizagem ao longo da vida e para todos. No mesmo ano do Conselho de Lisboa, em 2000, a União Europeia através do Relatório da Comissão sobre a Instrução e a Formação ao longo da vida formalizou a necessidade de reconhecer as aprendizagens não-formais e informais e introduziu o conceito de aprendizagem ao longo da vida (Commissione Europea, 2000b).

A aprendizagem consiste na aquisição ou na modificação de comportamentos, conhecimentos, habilidades, valores ou preferências e pode envolver a síntese de diferentes tipos de informação (Commissione Europea, 2001). A aprendizagem ao longo da vida ou permanente é uma abordagem compartilhada na Europa, em particular modo, na Itália, mas também no Brasil.

O conceito de aprendizagem ao longo da vida faz referência neste artigo ao quanto indicado pela Comissão Europeia, ou seja, a aprendizagem ao longo da vida ou permanente é qualquer atividade de aprendizagem realizada em qualquer momento da vida, com o objetivo de melhorar os conhecimentos, as capacidades e as competências numa prospectiva pessoal, cívica, social e/ou de emprego (Commissione Europea, 2001).

Após a realização da Conferência Geral da Organização Internacional do Trabalho (Oit, 2004), em Genebra, o Brasil também afirmou a importância de reforçar a aprendizagem ao longo da vida, para investir e criar as condições para melhorar a educação e a formação em todos os níveis. 
O Brasil reconhece que a educação, a formação e a aprendizagem ao longo da vida contribuem significativamente para a promoção dos interesses dos indivíduos, das empresas, da economia e da sociedade como um todo, principalmente considerando a importância fundamental de atingir o pleno emprego, a redução da pobreza, inclusão social e crescimento econômico sustentável em uma economia globalizada (Oit, 2004).

A aprendizagem ao longo da vida ou permanente é um processo constante de aprendizagem (do ato de aprender), seja comportamental que intelectual e deve abranger a inteira vida de um indivíduo. A importância dada às aprendizagens não-formais e informais é muito recente e ainda controversa. Durante décadas, as escolas modernas e contemporâneas na Europa são o contexto social onde é reconhecida e realizada a validação das aprendizagens dos indivíduos. Por validação se entende o ato de tornar claro ou evidente, de atribuir um valor ou um significado a aprendizagem desenvolvida (Commissione Europea, 2002).

Isso acontece não só através do sistema formal de educação e de formação, mas também através dos canais não-formais e informais (Cedefop, 2009).

A aprendizagem formal é a aprendizagem dedicada a um contexto organizado e estruturado (por exemplo, em uma instituição educativa, de formação ou de trabalho), especialmente concebida como tal (em termos de objetivos de aprendizagem, tempo e recursos para a aprendizagem); esta aprendizagem é intencional do ponto de vista do aluno e normalmente resulta em uma validação e certificação. A aprendizagem não formal é concebida através de atividades planejadas e não especificamente entendidas como aprendizagem (em termos de objetivos, de duração e de recursos); esta aprendizagem é intencional do ponto de vista do aluno. A aprendizagem informal é a aprendizagem decorrente das atividades da vida quotidiana, relacionadas ao trabalho, à família e ao lazer; não é estruturada em termos de objetivos, tempo e recursos de aprendizagem e na maioria dos casos, a aprendizagem informal não é intencional a partir do ponto de vista do aluno (Cedefop, 2009).

$\mathrm{O}$ reconhecimento destas formas de aprendizagem, que podem ser validáveis e certificáveis, na Europa e no mundo, faz parte de recentes estratégias de desenvolvimento da educação e da educação de adultos, ou seja, que valoriza as aprendizagens adquiridas em todo o arco da vida. A valorização das aprendizagens adquiridas se configura, de fato, também como uma forma de direito das pessoas em capitalizar e usar as próprias competências profissionais, independentemente de como essas foram adquiridas e desenvolvidas (Regione Veneto, 2012).

Para valorizar essas aprendizagens é necessário ter claros alguns conceitos que orientam o trabalho de 
reconhecimento e de certificação das mesmas. Trata-se dos conceitos de conhecimento, de habilidade e de competência que busca identificar as experiências vividas pelo indivíduo.

Neste artigo leva-se em consideração o conceito de conhecimento como "resultado da assimilação de informações através das aprendizagens" (Commissione Europea, 2009). Os conhecimentos podem ser tanto teóricos como práticos acerca de um fenômeno ou de um fato.

As habilidades "indicam as capacidades em aplicar os conhecimentos e em utilizar o know-how para poder concluir tarefas e solucionar problemas" (Commissione Europea, 2009).

As habilidades podem ser cognitivas (linguagem, compreensão, memória e aprendizagem, concentração e atenção, orientação, capacidade de ler e escrever, de fazer cálculos, de julgar, de pensamento abstrato, de planejamento, de organização e de inibição do comportamento, de movimento voluntário, de processamento visual, de consciência, etc.) e práticas (utilização de métodos, materiais e ferramentas, destreza manual, etc.) (Commissione Europea, 2009).

Por competência se entende a "comprovada capacidade de utilizar o conhecimento, as habilidades e as capacidades pessoais, sociais e/ou metodológicas, em situações de trabalho ou de estudo e no desenvolvimento profissional e pessoal" (Commissione Europea, 2009).

Tanto no contexto Europeu, na Itália e no Brasil, o conceito de competência é percebido de forma diferente, de acordo com o ambiente em que ele está inserido, ou seja, a competência pode ser associada ao mundo das empresas, ao sistema de instrução e de formação profissional e também aos contextos não-formais de aprendizagem, como na vida cotidiana, na família, na vida social ou no lazer. Além disso, a competência poder assumir valências diferentes, tais como: referir-se a uma atividade ou a uma profissão, relacionar-se com o desempenho de um determinado trabalho, determinar níveis de autonomia e de inovação, determinar critérios para desenvolver uma atividade, estabelecer modelos de autoridade e de divisão de tarefas e de aquisição de saberes (formais e informais), identificar processos de ação e de decisão, dentre outros quesitos. (Ajello, 2002).

Outro importante componente do conceito de competência é o contexto histórico ao qual ela está inserida, pois, se para haver uma determinada competência é necessário se comprovar determinados conhecimentos, determinadas habilidades e também determinadas capacidades pessoais, isso quer dizer que a competência é composta, sobretudo de elementos intrínsecos, que se desenvolvem em contato com o mundo 
externo e se relacionam a um momento histórico vivido. Nessa conjuntura histórica e social, as competências podem estar em constante movimento, sendo renovadas e reestruturadas em um fluxo contínuo (Cambi, 2004).

Assim, quando se fala de aprendizagem ao longo da vida, de contextos diferentes para desenvolvê-las e principalmente de como reconhecer as aprendizagens adquiridas através das competências (conhecimentos, habilidades e capacidades pessoais) é fundamental ter claro todos esses conceitos envolvidos, para facilitar o entendimento teórico e prático entre os sistemas e os territórios envolvidos, mas, sobretudo, para guiar a forma como são avaliadas e certificadas as competências dos indivíduos. A certificação das competências faz parte dos instrumentos que facilitam a participação ao processo de atualização e de crescimento do indivíduo e de suporte e acompanhamento às transformações da sociedade, que constitui uma prioridade estratégica para tornar transparente e comunicável as aprendizagens formais, não-formais e informais. Nos próximos parágrafos verificase o contexto europeu, particularmente na Itália, e, no Brasil a respeito do processo de validação e certificação das aprendizagens.

\title{
O CONTEXTO EUROPEU (ITÁLIA) SOBRE A CERTIFICAÇÃO DAS APRENDIZAGENS
}

A certificação das aprendizagens em diferentes contextos educativos e formativos tornou-se um prérequisito nos Países europeus. Vários estudos têm sido lançados com o objetivo de se comparar e se analisar os sistemas de certificação de competências em matéria de educação e de formação profissional, a fim de melhorar a transparência das qualificações e de promover a empregabilidade dos jovens.

\begin{abstract}
A questão da validação e certificação de competências tem sido abordada a nível europeu desde o final da década de oitenta, também para tentar resolver os problemas decorrentes da mobilidade no mundo dos negócios, ou seja, a forma de reconhecer as qualificações das pessoas que se deslocam de um país para o outro no mercado de trabalho europeu (Pellerey, 2013, p. 1).
\end{abstract}

Nas últimas décadas, os sistemas formais de instrução superior na Europa têm experimentado um processo de transformação, especialmente após a implementação do Processo de Bolonha, em 1999, organizado através de uma Conferência dos Ministros de Instrução Superior, a fim 
de criar um Espaço Europeu de Instrução Superior que é baseado em um acordo intergovernamental de cooperação, que depois foi formalmente assinado na Conferência Ministerial realizada em Budapeste e Viena, em março, 2010 (Commissione Europea, 1999).

O objetivo do Processo de Bolonha é o de promover a mobilidade por meio da aquisição e certificação de competências e o desenvolvimento da aprendizagem ao longo da vida no ensino superior, como um recurso de apoio aos sistemas econômicos e sociais da sociedade do conhecimento. "Os meios para alcançar tais objetivos são o apoio a uma maior comparabilidade e compatibilidade entre os diferentes sistemas e as diversas instituições de Instrução Superior na Europa e a melhoria da sua qualidade" (Grano; Ricci, 1999, p. 2).

Até mesmo no Conselho Europeu de Lisboa, de Março de 2000, foi reiterada a importância de uma maior transparência das qualificações e de tornar os sistemas europeus de instrução e de formação mais adequados às novas exigências da sociedade do conhecimento em termos de nível da qualidade da empregabilidade e da formação permanente.

Assim, em março de 2002, através do Conselho Europeu di Barcelona e também através da declaração de Copenhaga, de 30 de novembro de 2002 (Commissione Europea, 2002), foi solicitado aos Estados Membros ações para aumentar a transparência na instrução e na formação profissional com a atuação de instrumentos e de redes de informação, assim, depois foram adotadas algumas recomendações, hoje presentes em toda Europa:

1. O Quadro Europeu de Qualificações (European Qualification Framework - EQF) para a transparência das qualificações e das competências;

2. A Metodologia para a transferência de créditos para a instrução e formação Professional (European Credit system for Vocational Educational and Traning - ECVET);

3. O Quadro de referência para assegurar a qualidade (European Quality Assurance Reference Framework for Vocational Educationand Traning - EQAVET).

Na Declaração de Copenhaga, de 2002, evidenciouse, ainda, a importância de criar dentro da União Europeia, a mobilidade dos trabalhadores e dos estudantes, ampliando os padrões de empregabilidade entre os Países. Com essas e outras recomendações que visam uma maior cooperação entre os Países europeus em matéria de instrução e formação profissional foi estabelecido em 2003 um quadro único para a transparência das qualificações e 
das competências, denominado Europass (Commissione Europea, 2014). O Europass é um portfólio de documentos que o indivíduo poderá utilizar para apresentar as próprias qualificações e competências na Europa. O portfólio é composto dos seguintes documentos:

- $\quad$ Curriculum Vitae Europeu, que ajuda a mostrar as competências e as qualificações de forma mais eficaz;

- $\quad$ Passaporte de Línguas, que é uma ferramenta de autoavaliação das competências linguísticas e das qualificações.

- $\quad$ Europass Mobility, que registra os conhecimentos e as competências adquiridas em outro País europeu;

- Suplemento ao Certificado, que descreve os conhecimentos e competências adquiridas na educação e formação profissional.

- $\quad$ Suplemento ao Diploma, que descreve os conhecimentos e as competências adquiridas no ensino superior (Commissione $\mathrm{Eu}-$ ropea, 2014).

Portanto, todos esses instrumentos criados e implementados na União Europeia visam, além da transparência e reconhecimento das qualificações, criar possibilidades de mobilidade entre os estudantes e trabalhadores dos Países europeus.

$\mathrm{Na}$ estratégia europeia de emprego, se define de forma sempre mais explícita a ideia de um direito de aprendizagem e de formação não só ligada às estratégias dos sistemas de educação e de formação profissional, mas também de empregabilidade (Alessandrini, 2013, p. 1).

Para lidar com a mudança contínua do mercado de trabalho que requer habilidades cada vez mais elevadas e atualizadas, torna-se essencial à promoção da mobilidade e da empregabilidade. Assim, foi concebido o Espaço Europeu de Aprendizagem Permanente, com o objetivo

por um lado, de colocar os cidadãos capazes de circular livremente entre contextos de aprendizagem, trabalhos, regiões e Países, aproveitando ao máximo os seus conhecimentos e competências e, por outro, para que a União Europeia e os Países afiliados possam atingir os seus objetivos em termos de prosperidade, de integração, de tolerância e de democracia (Commissione Europea, 2001, p. 3). 
A definição de aprendizagem permanente utilizada nos documentos europeus é: "qualquer atividade de aprendizagem realizada em qualquer momento da vida e de forma continuativa a fim de melhorar os conhecimentos, as habilidades e as competências" (Commissione Europea, 2001, p. 41).

As expressões mais usadas para descrever a aprendizagem permanente são "lifelong learning, formação permanente, aprendizagem permanente, educação de adultos, que entraram para fazer parte de uma linguagem comum" (Alberici, 2002, p. 15). Nas orientações europeias sobre a validação das aprendizagens não-formais e informais, a European Centre for the Development of Vocational Training - CEDEFOP (2009), evidencia que a aprendizagem é caracterizada pelos resultados obtidos a partir de qualquer atividade que envolva um pleno significado ou por habilidades que podem ser adquiridas a partir de uma determinada experiência. Assim, com o objetivo de tornar reconhecíveis esses aprendizados, a Comissão Europeia apoia o desenvolvimento da validação da aprendizagem não-formal e informal a nível europeu, nacional e local.

\begin{abstract}
A certificação das aprendizagens não-formais e informais é vista como uma forma de completar cada vez mais o conceito de aprendizagem permanente. Outros países europeus sublinham a importância de tornar visível e valorizar a aprendizagem que ocorre fora das instituições de educação e de formação, por exemplo, no trabalho, nas atividades relacionadas ao lazer e em casa (Cedefop, 2009, p. 7).
\end{abstract}

A certificação das aprendizagens visa à valorização e à transparência das competências adquiridas pelos indivíduos nos diferentes sistemas de educação e de formação e também em diferentes contextos daqueles formais, como no ambiente de trabalho ou nas experiências vividas pelo sujeito, que não ocorre uma qualificação formal, e que, portanto, dificilmente permitem a demonstração de tais habilidades e competências, dificultando o desenvolvimento de uma carreira.

Do ponto de vista individual a validação das aprendizagens da pessoa oferece:

- $\quad$ possibilidade de uma melhor empregabilidade;

- novas oportunidades para aqueles que deixaram os estudos prematuramente;

- melhor acesso à formação e à educação formal;

- $\quad$ motivação mais forte para aprender; 
- desenvolvimento de planos de carreira coerente com as experiências (Regione Veneto, 2012, p. 9).

Ampliando a perspectiva e direcionando para o mercado de trabalho, as vantagens são:

- maior transparência das competências da força de trabalho;

- melhor correspondência entre as competências e a procura de trabalho;

- promoção da transferência de competências entre as empresas e entre os setores;

- facilitação da mobilidade no mercado de trabalho europeu (Regione Veneto, 2012, p. 9).

Neste sentido, é oportuno promover a validação dos resultados da aprendizagem não formal e informal, em consonância com a recomendação do Parlamento Europeu e do Conselho, de 23 de Abril de 2008, sobre a criação do Quadro Europeu de Qualificações para a aprendizagem ao longo da vida (Commissione Europea, 2008). Para promover este processo de validação é necessário:

o envolvimento dos parceiros sociais (organizações patronais, sindicatos, câmaras de comércio, indústria e artesanato) é, portanto, essencial para promover e facilitar a validação das aprendizagens adquiridas, em contextos de trabalho, usando dispositivos apropriados, assim como é necessário à participação das instituições de educação e de formação para facilitar o acesso à formação formal baseando-se em aprendizagens adquiridas, também em contextos de extraescolares (Regione Veneto, 2012, p. 6).

O Quadro Europeu de Qualificações, conhecido como QEQ, oferece um sistema comum de conhecimentos, habilidades e competências a serem desenvolvidas entre os diferentes sistemas de qualificações e respectivos níveis, seja de instrução geral e superior ou de formação profissional (Commissione Europea, 2008).

OQEQ, além de dar orientações sobre as competências que devem ser formadas, deve promover uma cultura de aprendizagem para todos. Segundo a União Europeia, esse quadro define alguns standard que devem ser desenvolvidos e avaliados através de competências, promovendo a transferência de créditos, um mútuo reconhecimento e enfatizando novos sistemas de certificação a nível europeu. Em particular modo, para poder criar e melhorar novos 
postos de trabalho, em vista da promoção da mobilidade entre trabalhadores; é fundamental que o QEQ seja adotado por todos os Países Membros, desenvolvendo ações recíprocas de desenvolvimento e de reconhecimento de competências e de qualificações em todo arco da vida (Commissione Europea, 2008).

A Comissão Europeia (Commissione Europea, 2012) visa proporcionar às pessoas a oportunidade de demonstrar o que aprenderam fora da educação e da formação formal e, mediante as experiências de mobilidade, de fazer uso de tal aprendizado para a carreira profissional e continuar a aprender.

Assim, foi determinado o processo de validação das aprendizagens não-formais e informais, assim sintetizadas:

- identificação dos resultados das aprendizagens adquiridas pela pessoa através dos canais não formal e informal;

- documentação dos resultados das aprendizagens adquiridas pela pessoa mediante as aprendizagens não formal e informal;

- avaliação dos resultados das aprendizagens adquiridas;

- $\quad$ certificação da avaliação dos resultados das aprendizagens não formal e informal, sob forma de qualificação ou créditos que contribuem para a obtenção de uma qualificação ou, se for caso disso, outra forma (Commissione Europea, 2012, p. 3).

A validação das aprendizagens é feita através da aplicação desse processo, considerando as necessidades e as peculiaridades nacionais, regionais e/ou locais, de fato, há um esforço crescente em desenvolver projetos ou apoiar iniciativas que promovam a melhoria das competências adquiridas (Commissione Europea, 2012).

Com relação à certificação das aprendizagens na Itália, de acordo com as indicações da União Europeia são implementados e compartilhados os instrumentos de reconhecimento dos diplomas, das competências, das profissões e do sistema de créditos.

O contexto italiano é coerente com as estratégias e ações da União Europeia em termos de certificação e reconhecimento das aprendizagens, especialmente para o ensino médio e para o ensino superior, quase sempre para avaliar e certificar o aprendizado adquirido através do sistema formal de ensino, enquanto ainda é difícil avaliar e validar as aprendizagens não-formais e informais (Cedefop, 2014). 
Para Nicoli e Tacconi "a realidade italiana é extremamente rica de normas e de acordos que tratam de standard, de certificação de competências e de créditos formativos [...] contrasta com a escassez de práticas reais correspondentes a tais regulamentos" (Nicoli; Tacconi, 2007, p. 127).

As questões que envolvem a transparência das competências e qualificações, a validação das aprendizagens não-formais e informais, a acumulação e transferência dos learning outcome (resultados das aprendizagens) de um contexto para outro requer a aplicação de dispositivos comunitários, que possam ser utilizados igualmente por todos.

Essas solicitações, ao longo dos anos, especialmente na Itália, estão sendo respondidas com iniciativas e projetos que visam à experimentação de alguns instrumentos. Através dessas experimentações, foram desenvolvidas metodologias, ferramentas e práticas centradas na concepção e implementação das qualificações em termos de resultados das aprendizagens, de validação das aprendizagens adquiridas, em contextos não formal e informal, inclusive na transferência de créditos educativos/ formativos, descritos anteriormente (Commissione Europea, 2009).

Sobre o reconhecimento, a certificação e a validação das aprendizagens não-formais e informais, a Itália aderiu completamente aos princípios da estratégia europeia visando à empregabilidade e o crescimento dos seus cidadãos. Mas, não existe um instrumento definido e gerido a nível nacional, apesar de existir um reconhecimento institucional com medidas legislativas de reforma do sistema educativo e do mercado de trabalho que emergem na necessidade de definir um sistema nacional de certificação de competências na formação profissional, tais como: o Acordo para o Trabalho entre o governo e as partes sociais de 1996, que reconhece a introdução de um sistema de certificação dos percursos formativos e das competências adquiridas; a Lei Treu 59/97; a Lei Bassanini 59/97; o Pacto Social para o desenvolvimento e a empregabilidade de 1998; o Acordo de Estados e Regiões de 2000; a Lei 53/2003, que reordenou todos os níveis de instrução e formação; a Lei 30/2003, que evidenciou a importância de alternância entre escola/formação e mercado de trabalho e a criação do currículo do cidadão (para a certificação das aprendizagens adquiridas em diferentes contextos); e, através a Gazeta Oficial de 2005, a apresentação da Caderneta do Cidadão; enfim, através da Conferência de Estados e Regiões em 2004, a definição dos standard mínimos de competências para o ensino técnico e profissional (Riello, 2013).

Defato, durante a Conferência entre Estados e Regiões de 2012, na Itália, confirmou-se o objetivo de construir um sistema nacional das profissões e de certificação de 
competências, colocando em evidência que a valorização das aprendizagens adquiridas em contextos de trabalho e de vida quotidiana representa um elemento fundamental das políticas públicas em tema de trabalho, de formação e de inclusão social. Além disso, esclareceu que o repertório de competências nacionais e regionais deve ser descrito em termos de competência e relacionado com o QEQ (Riello, 2013).

Ainda em 2012, o governo italiano, através da reforma do contrato de Apprendistato, o Decreto Legislativo de 26 de setembro de 2012, definiu os princípios, as características, as orientações metodológicas e os standard mínimos que compõem o Sistema Nacional de Certificação de Competências. Na Itália, o termo Apprendistato significa Contrato de Aprendizagem e indica um tipo de relação de trabalho com o objetivo de formação profissional e inserção no mercado de trabalho. Atualmente, o contrato de aprendizagem é o único contrato de trabalho com a função de formar/profissionalizar e é regulado pelo Decreto. 276 de 2003, que identifica três formas/contextos de validação das aprendizagens: aprendizagem para o cumprimento do direito e do dever de educação e de formação profissional; aprendizagem profissional para a obtenção de uma qualificação por meio de treinamento no local de trabalho e de aprendizagem técnica e profissional e aprendizagem para obter um diploma ou uma formação avançada (Ministero del Lavoro e delle Politiche Sociali, 2012).

Esse sistema faz referência à certificação das aprendizagens nos três contextos, formal, não-formal e informal, além de evidenciar o reconhecimento de tais aprendizagens em termos de créditos educativos/ formativos e de comprometer as partes envolvidas comações de cooperação interinstitucional para o desenvolvimento de propostas que visam à confiabilidade, à portabilidade, à qualificação do processo e dos produtos de certificação (Ministero del Lavoro e delle Politiche Sociali, 2012).

A estratégia italiana, em linha com as orientações europeias, visa à integração entre a aprendizagem e o trabalho para facilitar a empregabilidade dos jovens e constitui uma importante concepção de reforma da instrução e da formação profissional em uma ótica de integração e de diálogo entre os sistemas de instrução e o mercado de trabalho (Ministero del Lavoro e delle Politiche Sociali, 2012). Nesse sentido, várias iniciativas, projetos, reflexões foram introduzidas para valorizar e confirmar o princípio da certificação de todas as aprendizagens.

Com o Decreto Legislativo n.16, de janeiro de 2013, o governo italiano definiu a aplicação prática desse sistema nacional de certificação de competências, individuando as normas gerais e os níveis essenciais de desempenho para facilitar a validação das aprendizagens não-formais e informais e os standard mínimos de serviço desse sistema. 
O sistema italiano de certificação de competências, seguindo o modelo de certificação a nível europeu, propõe as seguintes fases de validação:

- identificação, que tem como objetivo identificar e revelar as habilidades de uma pessoa devido a uma ou mais qualificações; em caso de aprendizagem não-formal e informal essa fase envolve o suporte de uma pessoa na análise e na documentação da experiência de aprendizagem, na possibilidade de correlacionar e resultar em uma ou mais qualificações;

- avaliação, fase que determina a posse de uma ou mais competências relacionadas a uma ou mais qualificações; em caso aprendizagem não formal e informal essa fase envolve a adoção de métodos específicos de avaliação para a identificação das evidências que comprovam as competências adquiridas;

- certificação, fase que visa à emissão de documentos de validação ou certificação, documentando as competências identificadas e validadas que reconduzem a uma ou mais qualificações;

- adoção de medidas personalizadas de informação e orientação para os beneficiários dos serviços de identificação e validação e certificação de competências (Ministero dell'Istruzione, dell'Università e della Ricerca [MIUR], 2013, p.8).

Esse processo de validação e certificação de competências, adotado pelo governo italiano, seguindo as orientações europeias, é realizado através de organismos públicos e obedece aos seguintes critérios de certificação: denominação e descrição das competências, com indicação do nível de aprendizagem e seguindo o Quadro Europeu das Qualificações - QEQ; quando necessário, identificar o Código da Atividade Econômica - ATECO, a Nomenclatura e a Classificação das Unidades Profissionais - CP-ISTAT; inserir os dados relativos às modalidades de aprendizagem $\mathrm{e}$ à avaliação das competências, indicando os dados essenciais sobre a experiência vivida e o registro dos documentos de validação e de certificação das aprendizagens.

Além disso, a atestação possui como elementos fundamentais: os dados pessoais, os dados do organismo público com os dados da acreditação e as competências adquiridas pelo individuo com indicação das evidências, do repertório de competências e das qualificações de referência.

Para facilitar o reconhecimento de créditos educativos/formativos e até mesmo de uma efetiva qualificação, o governo italiano instituiu através da Lei de 28 de Junho de 2012, n. 92, artigo 4, parágrafo 67, um repertório nacional das qualificações de ensino, de 
formação e de qualificação, que consiste em um quadro de títulos de instrução e formação profissional composto de elementos essenciais e descritivos que são compartilhados em toda Europa, facilitando o reconhecimento de créditos e promovendo a mobilidade dos estudantes em todo território europeu (Alberici; Di Rienzo, 2013).

Por muitos anos procurou-se definir um sistema de certificação das competências para possibilitar a todos os cidadãos, a certificação das competências adquiridas na escola/universidade e no trabalho. Certamente, a iniciativa do governo italiano é válida e finalmente, parece que, é chegada a ocasião de valorizar e reconhecer as aprendizagens não-formais e informais. Porém, tais instrumentos e processos têm se mostrado de caráter burocrático, dificultando a realização e a viabilização da aplicação desse sistema na esfera pública. Outro fator é a questão de que as aprendizagens informais, não cabendo um documento de atestação e de realização da mesma (ausência de evidências), na maioria dos casos, a avaliação é realizada através de um processo de autoavaliação, a partir do próprio indivíduo, criando irregularidades nas relações de trabalho e de instrução.

Mesmo que a aplicação desse sistema de certificação de competências dependa ainda de uma predisposição funcional e prática dos seus instrumentos de identificação e de certificação das aprendizagens, nos próximos anos, espera-se que todas as regiões italianas possam convergir progressivamente sobre esses critérios e esses instrumentos para atender a especificidade dos territórios e garantir sua eficácia, com a adoção desse sistema que responde às estratégias e às orientações de cunho europeu.

A validação das aprendizagens não constitui somente uma resposta às exigências do mercado de trabalho, mas também um pilar de um novo modelo social. Segundo Di Rienzo e Alberici (2010), reconhecer e certificar as competências não-formais e informais é um processo dinâmico e social, centralizado na abordagem biográfica e capaz de dar respostas às complexidades dos processos educativos e formativos.

Em geral, percebe-se a necessidade de adaptação dos sistemas de educação e de formação em decorrência das transformações da sociedade e, portanto, a definição de políticas que respondam de forma crítica às mudanças na vida social, econômica e cultural.

\section{O CONTEXTO BRASILEIRO SOBRE A CERTI- FICAÇÃO DAS APRENDIZAGENS}

No caso do Brasil, por meio do Ministério da Educação, na LDBN - Lei de Diretrizes e Bases da Educação 
Nacional (Ministério da Educação [MEC], Lei n. ${ }^{\circ}$ 9394/96 e no Parecer 40/2004, do Conselho Nacional de Educação, iniciou-se a construção de um quadro de reconhecimento de competências com as diretrizes voltadas para o mercado de trabalho e para o emprego. Com isso, surgiram várias iniciativas para reconhecer e validar as competências acumuladas, até mesmo fora dos espaços formais e ao longo da vida.

O Ministério da Educação, por meio da Lei de Diretrizes e Bases da Educação (LDBN), Lei n. ${ }^{\circ}$ 9394/96, organizou e estabeleceu as Diretrizes Curriculares Nacionais (DCNs), que consistem em um conjunto articulado de etapas e modalidades da Educação Básica, além de descreverem as competências e as habilidades básicas, indicam a carga horária mínima necessária para a obtenção de um diploma ou de uma habilitação profissional (Mec, 1997).

Já a avaliação e a certificação de competências foram introduzidas pelo Decreto $\mathrm{n}^{\mathrm{O}}$ 2208/97, substituído em 2004 pelo Decreto n. 5154, finalizado ao sistema escolar, e não ao mercado de trabalho. Este decreto exigia que os sistemas de ensino federais e estaduais organizassem por meio de exames, a certificação de competências para permitir, de acordo com os créditos obtidos, a redução ou a integração do currículo, facilitando a integração através de módulos formativos, de modo a conferir a emissão do diploma (Mec, 2004).

Essa decisão foi tomada com base no artigo 41 da Lei $\mathrm{n}^{0}$. 9396/96 (Mec, 1996), que reconhece a capacidade de avaliar, reconhecer e certificar os conhecimentos adquiridos no campo da educação profissional e do trabalho. Sob este ponto de vista, a certificação de competências tornouse uma ferramenta adicional nas estruturas de formação profissional, mas não eliminou e nem substituiu as relativas qualificações profissionais.

Com isso, o desenvolvimento de competências, ou seja, os conhecimentos, as habilidades e as capacidades pessoais que os estudantes precisam adquirir ao longo de sua formação devem basear-se através de um referencial de competências a serem desenvolvidas. No Brasil, existem duas perspectivas que favorecem essa abordagem de competências.

A primeira visa à valorização das experiências de trabalho e de autodidática dos trabalhadores, com a intenção de criar ou de aumentar o empoderamento (em inglês empowerment) do indivíduo, ou seja, o potencial humano que, por vezes, permanece escondido e deve ser devidamente identificado, avaliado, reconhecido, desenvolvido e certificado (Mec, 1997).

A segunda perspectiva permite responder de forma mais rápida e flexível às necessidades do mercado de 
trabalho, que muda constantemente os perfis profissionais e suas formas de avaliação da competência em face da mudança tecnológica e organizacional contínua no mundo do trabalho (Mec, 1997).

Considerando tais perspectivas, o Governo Federal Brasileiro, em 2004, através do Decreto Ministerial n. 24, organizou a Comissão Interministerial de Certificação Profissional. Essa Comissão realizou vários estudos com base em experiências de outros países, como Espanha, França e Itália, que também participaram do Seminário Internacional de Certificação Profissional (Comissão Interministerial de Certificação Profissional, 2005), organizado pela Comissão entre 7 e 9 de Novembro de 2005, em Brasília.

Tal experiência serviu de referência para o desenvolvimento de uma proposta do governo para a criação do Sistema Nacional de Certificação Profissional - SNCP, cuja finalidade é a de "regular os processos de certificação profissional no Brasil, promovendo a elevação do nível de escolaridade dos cidadãos, assegurando a continuidade de estudos e articulando as diversas modalidades, iniciativas e as experiências de certificação existentes" (Comissão Interministerial de Certificação Profissional, 2005, p. 2). Além disso, esse sistema de certificação pretende promover:

- a aprendizagem permanente e a melhoria constante da qualificação do/a trabalhador/a brasileiro/a;

- o acesso, permanência e progressão no mundo do trabalho;

- a participação ativa de representações empresariais, sindicais, governamentais, educacionais e certificadoras;

- a adequada articulação entre os diferentes órgãos governamentais envolvidos com a certificação profissional; e

- a adequada integração com o Sistema Público de Emprego e os Sistemas da Educação Nacional (Comissão Interministerial de Certificação Profissional, 2005, p. 2).

A primeira proposta desse sistema foi a criação da Rede Nacional de Certificação Profissional e Formação Inicial e Continuada - Rede Certific. O Ministério do Trabalho e Emprego propôs a criação desta rede nacional de certificação ligada aos novos padrões de qualidade no setor de produção e pode ser definida como:

um programa de certificação dos conhecimentos adquiridos no curso da vida. Todos os profissionais (música, construção civil, turismo e hospitalidade, eletrônicos ou de pesca) 
que não têm uma certificação reconhecida, podem se comunicar com uma das 37 escolas que oferecem treinamento para obter o diploma. Os trabalhadores terão que avaliar suas habilidades e também obter cursos para melhorar a sua formação. Não há nenhum custo e as vagas são ilimitadas (Briasco, 2012, p. 9).

A Rede Certific foi regulamentada pela Portaria Interministerial (Ministério da Educação e Ministério do Trabalho e Emprego) $\mathrm{n}^{\circ}$ 1.082, de 20 de novembro de 2009, e é constituída "como uma Política Pública de Educação Profissional e Tecnológica voltada para o atendimento de trabalhadores, jovens e adultos que buscam o reconhecimento e certificação de saberes adquiridos em processos formais e não-formais de ensino-aprendizagem e formação inicial e continuada" (Mec, 2009).

A implementação da Rede Certific é reforçada pelo caráter público na certificação das competências e na articulação entre o Sistema Público de Emprego e o Sistema de Ensino, para responder as exigências sociais, principalmente ligadas ao aumento do nível de escolarização da população.

Para obter uma certificação desse tipo, isto é, que os conhecimentos, as habilidades e as capacidades profissionais possam ser reconhecidos através do Ministério da Educação e do Ministério do Trabalho e Emprego, o interessado deve dirigir-se a algum Instituto Federal de Educação, Ciência e Tecnologia, que seja acreditado pelo governo e que seja participante da Rede Certific no âmbito de interesse e solicitar o reconhecimento, que é constituído de duas etapas: inscrição por meio de edital público e reconhecimento dos saberes (Mec, 2009).

Outra iniciativa é a proposta do Ministério da Educação, ao lançar em 2011 o Programa Nacional de Acesso ao Ensino Técnico e Emprego - PRONATEC, por meio da Lei 11.513/2011, "que inclui um conjunto de ações que visam expandir a oferta de ensino profissional e tecnológica, tanto para cursos técnicos de nível médio como em cursos de formação inicial e contínua de formação profissional” (Briasco, 2012, p. 13).

O Pronatec busca ampliar as oportunidades educacionais e de formação profissional qualificada aos jovens, trabalhadores e beneficiários de programas de transferência de renda. Os cursos, financiados pelo Governo Federal, são ofertados de forma gratuita por instituições da Rede Federal de Educação Profissional, Científica e Tecnológica e das redes estaduais, distritais e municipais de educação profissional e tecnológica. Também são ofertantes as instituições do Sistema S, como o SENAI, SENAT, SENAC e SENAR. A partir de 2013, as instituições 
privadas, devidamente habilitadas pelo Ministério da Educação, também passaram a ser ofertantes dos cursos do Programa. De 2011 a 2014, por meio do Pronatec, foram realizadas mais de 8 milhões de matrículas, entre cursos técnicos e de formação inicial e continuada (Mec, 2011a).

Apesar dessas iniciativas e de outras, por exemplo, a criação do Catálogo Nacional de Cursos Técnicos e do Catálogo Nacional de Cursos Superiores de Tecnologia (MEC, 2011b), que favorecerem a certificação das aprendizagens adquiridas e a possibilidade de integrálas, no Brasil não há um quadro nacional de qualificações, assim como não é ainda bem definida a alternância entre a instrução e formação profissional com o mercado de trabalho. No entanto, todas essas iniciativas estão contribuindo para a formação do Quadro Nacional de Qualificações - QNQ, sobretudo com a importância dada, pelo governo e pelas esferas sociais no que concerne à abordagem de competências (Briasco, 2012).

A questão é que esse tema é muito discutido e a preocupaçãodosbrasileirosdizrespeitoàinstitucionalização de um sistema de certificação profissional que possa evitar uma exclusão dos trabalhadores, se orientada somente por objetivos de competitividade e de hierarquias sociais, desvalorizando as qualificações profissionais por conta de competências flexíveis e que estão sempre se renovando. Neste caso, a certificação não iria fornecer o reconhecimento das competências dos trabalhadores, proporcionando-lhes o direito de acesso ao sistema de ensino. Em vez disso, os certificados podem corresponder a mecanismos de classificação, de seleção e de exclusão do mercado de trabalho. Já dizia Perrenoud que "um plano de formação profissional não é o de dar lugar a todos os tipos de disciplinas, mas de implantar dispositivos de formação que permitam construir, realizar e avaliar competências" (Perrenoud, 1997).

De fato, o MEC (2009) enfatiza essa preocupação em direcionar a certificação das competências para a valorização dos saberes adquiridos na vida e no trabalho do indivíduo, oferecendo a oportunidade de complementação da formação quando necessária e estabelecendo princípios de legitimidade, de confiabilidade, de validade e de credibilidade nos processos de certificação das competências.

No que diz respeito à Educação de Jovens e Adultos - EJA (modalidade de ensino que oferta Ensino Fundamental e Médio para atendimento a jovens, adultos e idosos através de cursos, programas, projetos e exames), aos que, por algum motivo não conseguiram concluir o processo educativo e formativo, a certificação das competências é regulamentada pelo Decreto 5.478/2005. O referido Decreto institui o Programa de Integração da 
1 Dados referentes à Pesquisa Nacional por Amostra de Domicílios 2009/2011.
Educação Profissional ao Ensino Médio na modalidade de Educação de Jovens e Adultos - PROEJA, por meio do qual as instituições federais de educação tecnológica podem reconhecer, avaliar e certificar os conhecimentos, as habilidades e as capacidades extracurriculares. De fato, a ênfase é nas aprendizagens não-formais e informais que possam culminar em competências profissionais. Porém, depois da revogação desse Decreto, no ano seguinte foi promulgado o Decreto $\mathrm{n}^{\circ} 5.840$, de 13 de julho de 2006, com o objetivo de ampliar a abrangência do programa, incluindo o ensino fundamental, e de possibilitar que as instituições de ensino estaduais e municipais, as instituições privadas nacionais de serviço social, aprendizagem e formação profissional possam participar do PROEJA, denominado desde então, Programa Nacional de Integração da Educação Profissional com a Educação Básica na Modalidade de Educação de Jovens e Adultos (Mec, 2007).

Tal possibilidade de abrangência éfundamentalmente justificada pelo alto índice de pessoas que não concluíram o ensino fundamental, - o percentual é de $49,5 \%$ de jovens com mais de 25 anos que ainda não concluíram o ensino fundamental, o que representa 54,5 milhões de brasileiros ${ }^{1}$ (Instituto Brasileiro de Geografia e Estatística [IBGE], 2011).

Esse dado evidencia a necessidade de ampliar a abrangência do programa com a perspectiva de integração da educação profissional à educação básica, tendo como horizonte a universalização da educação básica, aliada à formação para o mundo do trabalho, com acolhimento específico de jovens e adultos com trajetórias escolares descontínuas (Mec, 2007).

A Educação de Jovens e Adultos - EJA, no Brasil, enfrenta muitos desafios, em particular modo, "o da formação do profissional, da organização curricular integrada, da utilização de metodologias e mecanismos de assistência que favoreçam a permanência e a aprendizagem do estudante, da falta de infraestrutura para oferta dos cursos dentre outros" (Mec, 2007). Essas iniciativas do governo brasileiro têm a finalidade de preparar os jovens para enfrentarem os desafios de uma economia globalizada, através de uma educação e de uma formação geral e profissional competente.

As políticas voltadas à implementação e as práticas da Educação de Jovens e Adultos - EJA devem possibilitar, além da alfabetização de adultos, a formação integral do indivíduo; devem oferecer uma formação continuada e também uma certificação das aprendizagens em todo arco da vida, em uma perspectiva de aprendizagem permanente (Mec, 2014).

Hoje, a certificação das competências do Ensino Fundamental, na modalidade EJA, é realizada através do Exame Nacional para Certificação de Competências de 
Jovens e Adultos - ENCCEJA, que avalia as competências, as habilidades e os saberes adquiridos tanto no processo escolar quanto no extracurricular; para o ensino médio as competências são avaliadas e certificadas através do Exame Nacional para o Ensino Médio - ENEM (Mec, 2014).

Em todas as práticas e iniciativas descritas do contexto brasileiro emerge a necessidade de cooperação entre as instituições de ensino, os organismos governamentais e não governamentais, as empresas e os trabalhadores para possibilitar a aplicação práticas das políticas que favorecem a certificação das aprendizagens em diferentes contextos, a fim de desenvolver uma rede colaborativa capaz de efetivar as transformações sociais que esperam os brasileiros (Urbano; Pereira, 2013).

\section{CONSIDERAÇÕES FINAIS}

O tema da aprendizagem permanente e da certificação das aprendizagens está na agenda de discussão política desde há muito tempo. No entanto, a partir do final dos anos de 1990, uma vez que foi reconhecida a importância deste setor, não somente para a evolução social e econômica, mas também para a coesão social e a cidadania ativa em uma economia baseada no conhecimento, tornouse gradualmente um tema prioritário de reflexão política em todo o mundo.

Os sistemas de educação e formação profissional devem fornecer às pessoas as competências básicas necessárias não somente a favor de um desenvolvimento econômico, é necessário garantir a todos os cidadãos, mesmo fora dos sistemas de instrução, a possibilidade de adquirir ou de atualizar os conhecimentos, as habilidades e as competências, possibilitando o crescimento do indivíduo e da sociedade. Além disso, é necessário empreender todos os esforços para avaliar e certificar as competências de uma forma séria, viável e segura, com base em diferentes contextos e com métodos apropriados e eficazes.

Quanto à certificação das aprendizagens, os maiores pontos críticos verificados são: a dificuldade de reconhecer as aprendizagens adquiridas através dos canais informais e não- formais em ambos os países (Comissão Interministerial de Certificação Profissional, 2005 e Commissione Europea, 2012); a falta de ferramentas ou a descontinuidade com que são realizadas as práticas que podem conduzir ao reconhecimento das aprendizagens; e a ausência ou dificuldade de implementação de um quadro comum de competências correspondentes à instrução e formação profissional.

Além disso, observa-se uma progressiva valorização das aprendizagens adquiridas ao longo da vida em 
detrimento da educação de adultos, que deixou de ser um subsistema da educação e passou a ser parte integrante dos processos que colocam no centro as aprendizagens adquiridas, desenvolvidas, reconhecidas e por fim certificadas.

A certificação das aprendizagens tornou-se uma estratégia para a empregabilidade das pessoas, mas também um fator de desenvolvimento social, uma vez que, favorece o crescimento do indivíduo em termos de conhecimentos, habilidades e capacidades pessoais.

Na Itália, assim como em todos os Países que fazem parte da União Europeia, a importância da validação das competências adquiridas através de processos nãoformais e informais de aprendizagem gerou uma série de experimentações para a construção de instrumentos que possibilitam a certificação das aprendizagens de um indivíduo; a dificuldade está na aplicação pratica dos dispositivos pela complexidade de operacionalização dos mesmos e na pouca interação entre os sistemas de ensino e os sistemas do mercado de trabalho.

Em uma sociedade em contínua evolução, a aprendizagem permanente deveria se tornar não só uma tarefa institucional, mas também um paradigma sobre a sua real função; e a abordagem de competência como uma formação reflexiva capaz de promover e facilitar uma aprendizagem significativa e de qualidade.

Em um contexto de aprendizagem permanente isso significa pensar e rever continuamente o que se aprende, reorganizando e atualizando todo o saber adquirido, potencializando, assim, a aprendizagem ao longo da vida.

No Brasil, várias ações, programas ou projetos visam a contribuir para a redução do analfabetismo e para o aumento da qualificação profissional com a elevação da escolaridade de trabalhadores jovens e adultos, sobretudo, em uma perspectiva de aprendizagem permanente. $\mathrm{O}$ impacto das políticas de certificação de competências, no Brasil, deve ser acompanhado e as dificuldades precisam ser superadas, principalmente ligadas ao acesso de todos que necessitam certificar as suas aprendizagens, que seja por motivo de acesso ao mercado de trabalho, de continuação dos estudos, de melhoramento das próprias habilidades e capacidades, de conclusão dos estudos, de novas possibilidades de carreira, de aumento da empregabilidade, ou de crescimento profissional e pessoal, dentre outras necessidades.

Além disso, todas essas iniciativas para valorizar as aprendizagens adquiridas em diferentes contextos, não-formais e informais, possibilitam a superação de uma dicotomia entre instrução e o mundo do trabalho, estabelecendo uma estreita ligação entre estas partes, principalmente quando se reconhece que a experiência é 
um lugar de produção de saberes relevantes e de formação/ desenvolvimento pessoal e profissional.

É necessário evidenciar que os mecanismos de certificação das aprendizagens devem atender ao propósito de redução da exclusão social, articulando a certificação aos processos de formação do indivíduo, para não se tornar um instrumento de classificação ou de exclusão do indivíduo na sociedade. Para isso, os sistemas de certificação devem levar em consideração as características regionais e as desigualdades presentes nos territórios.

Enfim, deve-se manter um contínuo controle na avaliação, no credenciamento e em todo o processo de certificação das aprendizagens. Não se pode negar o quanto é importante para o indivíduo e para a sociedade a organização e a valorização dos saberes, assim como a importância da certificação das aprendizagens que potencializa os saberes adquiridos e torna a aprendizagem mais significativa.

\section{REFERÊNCIAS}

AJELLO, Anna Maria. Apprendimento e competenza: un nodo attuale. n.1. Lecce: 2002. pp. 39-56. Disponível em http://www.edscuola.it/archivio/antologia/ scuolacitta/.Accesso em: 15 nov 2013.

ALBERICI, Aureliana; DI RIENZO, Paolo. Apprendimento Permanente e Università: La convalida dell'aprendimento non formale e informale. Scuola Democratica Scuola democratica: strategie educative e territorio, Bolonha, Il Mulino, n.1, fascículo, pp. 57-78, 1/2013.

ALBERICI, Aureliana. L'educazione degli adulti. Roma: Carocci, 2002.

ALESSANDRINI, Giuditta. Il Sistema di Certificazione di Competenze in Italia: Evoluzione e Prospettive. Roma: 2013. Disponível em: http://www.ciofs-fp.org/seminarioeuropa/materiali/relazioni/. Acesso em: 18 fev 2014.

BRIASCO, Irma. Brasil: Sistema Nacional de Qualificações Profissionais. Madri: 2012. Disponível em: http://pt.slideshare.net/EUROsociAL-II/informeeurosocial-sncp-brasil-portugues. Acesso em: 18 fev 2014.

CAMBI, FRANCO. Saperi e competenze. Roma-Bari: Laterza, 2004.

CENTRO EUROPEO PER LO SVILUPPO DELLA FORMAZIONE PROFESSIONALE [CEDEFOP]. Relazione sull'istruzione e formazione professionale (IFP) in Italia. Roma: 2014. Disponível em: http://www.cedefop.europa.eu/en/publications-andresources/publications/4132. Acesso em: 12 fev 2015. 
CENTRO EUROPEO PER LO SVILUPPO DELLA FORMAZIONE PROFESSIONALE [CEDEFOP]. European Guidelines for validating non-formal and informal learning. Luxembourg: 2009. Disponível em: http://www.cedefop.europa.eu/en/news/4041.aspx. Acesso em: 12 jun 2014.

COMMISSIONE EUROPEA. Europass: Aprire le porte allo studio e al lavoro in Europa. Roma: 2014. Disponível em: http://europass.cedefop.europa.eu/it/ about/history. Acesso em: jun, 2014.

COMMISSIONE EUROPEA. Raccomandazione del Consiglio del 20 dicembre 2012 sulla convalida dell'apprendimentonon-formaleeinformale. Roma: 2012. Disponível em: http://eur-lex.europa.eu/LexUriServ /LexUriServ.do?uri=OJ:C:2012:398:0001:0005:IT:PDF. Acesso em: o1 out 2014.

COMMISSIONE EUROPEA. Progetto Procedura Best: Imprenditorialità nell'Istruzione e nella Formazione Professionale. Relazione Finale Del gruppo di esperti. Roma: 2009. Disponível em: http://ec .europa.eu/enterprise/policies/sme/files/smes/vocational /entr_voca_it.pdf. Acesso em: 04 out 2014.

Raccomandazione del Parlamento Europeo e del Consiglio, del 23 aprile 2008 sulla costituzione del Quadro europeo delle qualifiche per l'apprendimento permanente. Roma: 2008. Disponível em: http://eur-lex.europa.eu/LexUriServ/ LexUriServ.do?uri=OJ:C:2008:111:0001:0007:it:PDF. Acesso em: 22 out 2014.

Dichiarazione dei ministri europei dell'istruzione e formazione professionale, e della Commissione europea, riuniti a Copenaghe nel 29 e 30 novembre 2002, su una maggiorecooperazioneeuropea in materia di istruzione e formazioneprofessionale. Roma: 2002. Disponível http://europa.eu/legislation_summaries/ education_training_youth/vocational_training/efoo18_ it.htm. Acesso em: 30 abr 2014.

Realizzare uno spazio europeo dell'apprendimento permanente. Roma: 2001. Disponível em: http://eur-lex.europa.eu/lexuriserv/ lexuriserv.do?uri=com:2001:0678:fin:it:pdf. Acesso em: 01 jan 2014.

Il Consiglio europeo straordinario di Lisbona: verso un'Europa dell'innovazione e della conoscenza. Roma: 2000a. Disponível em: http: //europa.eu/legislation_summaries/education_training youth/general_framework/c10241_it.htm. Acesso em: 01 jan 2014. 
COMMISSIONE EUROPEA. (200ob). Memorandum sull'istruzione e La formazione permanente. Disponível em: http://archivio.pubblica.istruzione.it/dg_postsecondaria/memorandum.pdf. Acesso em: 06 mar 2015 .

COMMISSIONE EUROPEA. Processo di Bologna: Dichiarazione congiunta dei ministri europei dell'Istruzione. Roma: 1999. Disponível em: http:// www.bolognaprocess.it/content/index.php?action=read cnt\&id_cnt=5718. Acesso em: 01 jan 2014.

COMISSÃO INTERMINISTERIAL DE CERTIFICAÇÃO PROFISSIONAL. Sistema Nacional de Certificação Profissional SNCP. Brasília: 2005. Disponível em: http://portal.mec.gov.br/setec/arquivos/pdf/certifica_ minuta.pdf. Acesso em: 01 jan 2014.

DI RIENZO, Paolo; ALBERICI, Aureliana. Il riconoscimento e La validazione degli apprendimenti non formali e informali nell'università. Roma: Anicia, 2010.

GRANO, Clara; RICCI, Alessia. (Ed.). (1999). Lo Spazio Europeo dell'Istruzione Superiore. Roma: 1999. Disponível em: http://www.indire.it/lucabas/lookmyweb/templates/up_files/Bologna_promoters/ Doc/Pubblicazioni/Lo\%20Spazio\%20Europeo\%20 dellIstruzione\%20Superiore. Acesso em: o8 set 2014.

MINISTÉRIO DA EDUCAÇÃO [MEC]. Lei de Diretrizes e Bases da Educação Nacional: Lei n. 9.394, de 20 de dezembro de 1996. 1996. Disponível em: http://portal. mec.gov.br/arquivos/pdf/ldb.pdf. Acesso em: 23 abr 2015.

Lei no 9.394, de 20 de Dezembro de 1996: Leis de Diretrizes e Bases da Educação Nacional. Brasília: 2006. Disponível em: http://www.planalto.gov. br/ccivil_03/leis/l9394.htm. Acesso em: 26 abr 2014.

.Estabelece as diretrizes operacionais para a educação profissional em nível nacional. Brasília: 1997. Disponível em: http://portal.mec.gov. $\mathrm{br} / \mathrm{setec} /$ arquivos/pdf_legislacao/rede/legisla_rede_ parecer1797.pdf. Acesso em: 23 abr 2015.

. Regulamenta o $\S 2^{\circ}$ do art. 36 e os arts. 39 a 41 da Lei no 9.394, de 20 de dezembro de 1996, que estabelece as diretrizes e bases da educação nacional, e dá outras providências. Brasília: 2004. Disponível em: http://www.planalto.gov.br/ccivil_03/_ ato2004-2006/2004/decreto/d5154.htm\#art9. Acesso em: 23 abr 2015 . 
Programa Nacional de Integração da Educação Profissional com a Educação Básica na modalidade de Educação de Jovens e Adultos. Brasília: 2007. Disponível em: http://portal.mec.gov.br/index.php?Itemid $=562 \&$ catid $=259:$ proeja $-\& i d=12288$ : programanacional-de-integracao-da-educacao-profissional-com-a-educacao-basica-na-modalidade-de-educacao-de-jovense-adultos-proeja\&option=com_content\&view=article . Acesso em: 29 mar 2015.

Rede Certific. Brasília: 2009. Disponível em:http://portal.mec.gov.br/index.php?option=com_con tent\&view=article\&id=15266\&Itemid=800. Acesso em: 29 mar 2015 .

O que é o PRONATEC?. Brasília: 2011a. Disponível em: http://pronatec.mec.gov.br/institucional90037/o-que-e-o-pronatec. Acesso em: 29 mar 2015.

Os caminhos da Qualificação Técnica e Profissional no Brasil. Brasília: 2011b. Disponível em: http://www.ipea.gov.br/agencia/images/stories/PDFs/ 110822_seminareducario5.pdf. Acesso em: 29 mar 2015.

Encceja. Brasília: 2014. Disponível em: http://portal.mec.gov.br/index.php?option =com content\&id=12485\&Itemid=784. Acesso em: 19 mar 2015.

MINISTERO DEL LAVORO E DELLE POLITICHE SOCIALI. Lavorare insieme per l'occupazione dei giovani. Roma: 2012. Disponível em: http://www.lavoro.gov.it/Documents/Resources/ConferenzaGiovani/ docInfoApprendistato_IT.pdf. Acesso em: 15 mar 2015.

MINISTERO DELL'ISTRUZIONE，DELL'UNIVERSITÀ E DELLA RICERCA. [MIUR]. Decreto Legislativo 29 gennaio 2013, n.13. Roma: 2013. Disponível em: http:// hubmiur.pubblica.istruzione.it/alfresco/d/d/workspace/ SpacesStore/co88ooef-8627-4444-beaa-79771e49a615/ avviso_250213_all.pdf Acesso em: 15 mar 2015.

NICOLI, Dario; TACCONI, Giuseppe. Valutazione e Certificazione degli apprendimenti: Ricognizione dello stato dell'arte e ricerca nella pratica educativa della Federazione CNOS-FAP. Roma: 2007. vol.1. Disponível em: http://www.ciofs-fp.org/download/ valutazione-e-certificazione-degli-apprendimentiricognizione-dello-stato-dellarte-e-ricerca-nella-pratica-educativa-della-federazione-cnos-fap/. Acesso em: 12 dez, 2013.

ORGANIZAÇÃO INTERNACIONAL DO TRABALHO [OIT]. Sobre o Desenvolvimento dos Recursos Humanos: Educação, Formação e Aprendizagem permanente. Brasília: 2004. Disponível em: http://portal.mte.gov.br/data/files/FF8080814295F16Do142FC71DFFFo 8A1/MorettoAmiltonJos\%C3\%A9\% 20 \%281\%29.pdf. Acesso em: 22 abr 2014. 
PELLEREY, Michele. La competenza professionale nel rapportotra formazione e occupazione. Roma: 2013. Disponível em: http://www.ciofs-fp.org/seminarioeuropa/materiali/relazioni/. Acesso em: 18 fev 2014.

PERRENOUD, Philippe. A qualidade de uma formação profissional é executada primeiramente em sua concepção. In Anais do Encontro de Profissionais da Saúde: Projeto qualidade de cuidados médicos, 1997. Marseille/França: CEFIEC.

REGIONE VENETO. Linee Guida per La Validazione di Competenze acquisite in contesti non formali ed informali: Valorizzazione del Capitale Umano. Veneza: 2012. Disponível em: http://www.regione.veneto .it/c/document_library/get_file?uuid=25b337e3-47b549c4-ba34-877709d85c21\&groupId=60642. Acesso em: 18 fev 2014.

RIELLO, Giorgio. La formatività nel processo di certificazione delle competenze. 2013. Tese (Doutorado) em Cognizione e della Formazione - Scuola Dottorale di Ateneo, Università degli studi di Venezia - Ca' Foscari, Veneza, 2013.

URBANO, Fernanda Santana De Souza; PEREIRA, Marcelo Urbano. A Rede Certific e a Certificação Profissional: uma nova institucionalidade para uma nova política?. In: VI Jornada Internacional de Políticas Públicas: $O$ desenvolvimento da crise capitalista e a atuação das lutas contra a exploração, a dominação e a humilhação, São Luíz, 2013 . 